\title{
Documentos de inteligência como fonte: o caso do Federal Bureau of Investigation (FBI)
}

\author{
João Paulo Martins Faria ${ }^{1}$
}

Resumo: A proposta deste artigo é explorar as potencialidades e os limites dos documentos de agências de inteligência como fonte para os historiadores. Para isso, será usado o caso dos documentos do Federal Bureau of Investigation (FBI), especialmente durante os anos 1950 e 1960, quando a instituição investigou e monitorou de forma intensa vários movimentos sociais nos Estados Unidos. Com um histórico bastante repressivo em relação a minorias, organizações de esquerda, e até movimentos supremacistas brancos, o FBI produziu documentação farta sobre seus investigados. Apesar disso, a discussão teórico-metodológica sobre as fontes dessa agência é insuficiente, dado o caráter recente da historiografia sobre a instituição e as limitações de acesso aos arquivos do Вигеаu. Utilizando como base teórica de análise estudos sobre a atividade de inteligência e considerações sobre arquivologia, pretende-se discutir o olhar do historiador sobre os documentos de agências de informação.

Palavras-chave: Estados Unidos; FBI; inteligência

\section{Intelligence documents as historical sources: a case study on the Federal Bureau of Investigation (FBI)}

\begin{abstract}
The aim of this article is to explore the possibilities and the limitations of intelligence agencies documents as historical sources, in particular the FBI files during the 1950s and the 1960s, when the agency was responsible for intense surveilling of social movements. Being an agency with a long history of repression towards minorities and left-wing organizations, the FBI produced a lot of documents on the subjects it investigated. However, theoretical and methodological discussions regarding those files are significantly short, due to the small amount of literature about the agency and severe limitations of access to the Bureau archives. Using approaches of the intelligence studies and considerations about archives, the making of history will be discussed through these kinds of writings.
\end{abstract}

Keywords: United States; FBI; intelligence

Artigo recebido em: 28/09/2020

Artigo aprovado para publicação em: 07/04/2021

\footnotetext{
${ }^{1}$ Mestrando em História Social pela Universidade de São Paulo (USP). Esse artigo é parte de uma pesquisa de mestrado em andamento, intitulada Estados Unidos, FBI e movimento negro: investigações das atividades de Malcolm X e Martin Luther King Jr. (1953-1968), sob orientação da Prof. ${ }^{\text {a } D r . ~}{ }^{a}$ Mary Anne Junqueira e com bolsa da Fundação para o Amparo à Pesquisa do Estado de São Paulo (FAPESP). E-mail para contato: joao.martins.faria@usp.br. Lattes: http://lattes.cnpq.br/3568624313421262.
} 
Introdução

O Federal Bureau of Investigation (FBI) é uma instituição governamental norteamericana encarregada do trabalho policial federal nos Estados Unidos e da atividade de inteligência interna. Ela responde ao U.S. Departmente of Justice (DOJ) e ao chefe deste, o attorney general (equivalente ao Ministro da Justiça no Brasil). Desde sua criação, no início do século XX, o Bureau foi uma instituição marcada pela repressão exercida sobre diversas minorias, grupos de esquerda e organizações supremacistas brancas. Embora seja uma agência importante na história do país, sua bibliografia é restrita e bastante recente, sendo objeto de estudo de historiadores a partir da década de 1980.

Por problemas de acesso aos arquivos da instituição e por questões relacionadas à memória daqueles que sofreram com a repressão do Bureau, a produção acadêmica sobre o FBI teve como proposta descrever investigações e acontecimentos que antes eram segredo de Estado. Nesse sentido, poucas reflexões metodológicas e teóricas foram produzidas acerca das fontes escritas da agência. $\mathrm{O}$ atentado do 11 de setembro renovou o interesse geral na instituição no século XXI, e novos livros sobre a trajetória dela foram escritos. No entanto, eles reproduziam narrativas teleológicas que tentavam entender como historicamente o Bureau se transformou numa organização que havia falhado na proteção nacional diante do terrorismo (FARIA, 2019, pp. 45-54).

Nosso objetivo com este artigo é tentar explorar - a partir de considerações sobre a atividade de inteligência e arquivologia — as potencialidades e os limites da documentação de instituições de inteligência no fazer do historiador, a partir do caso específico do FBI chefiado por John Edgar Hoover ${ }^{2}$. Com isso, nossa proposta é uma reflexão teórico-metodológica sobre a produção, circulação e interpretação dos documentos produzidos por essas agências.

Dividiremos o artigo em quatro partes. A primeira trata de uma contextualização para entendermos o FBI e sua trajetória da fundação até 1975, quando uma série de reformas reestruturou a agência. A segunda trata da documentação do Bureau e dos

\footnotetext{
${ }^{2}$ John Edgar Hoover (1895-1972) foi um advogado norte-americano e o primeiro e mais longevo diretor do FBI (1935-1972). Considerando sua atuação desde o Bureau of Investigation, foi seu $6^{\circ}$ diretor (19241935). O quartel-general do Bureau, localizado na capital Washington D. C., leva seu nome.
} 
problemas de acesso e censura nos escritos da instituição. A terceira parte discute a confiabilidade das fontes e como estas produzem imagens acerca dos investigados, utilizando como exemplo o caso da investigação de Martin Luther King Jr. Por fim, considerações sobre arquivologia serão trazidas à baila para entendermos como a documentação do FBI pode ser lida e interpretada.

\section{Trajetória do FBI (1908-1975)}

Em 1908, o governo de Theodore Roosevelt (1901-1909) e o então attorney general Charles Bonaparte criaram o BOI (Bureau of Investigation), uma força investigativa ligada ao Departamento de Justiça. A principal motivação para a criação da instituição foi a necessidade antiga do DOJ em ter uma força investigativa própria, já que anteriormente tomava de empréstimo agentes do U.S. Secret Service para suas investigações $^{3}$. O primeiro momento de maior importância do BOI foi durante a Primeira Guerra Mundial, quando o Bureau foi responsável pela vigilância de estrangeiros residentes ou recém-chegados aos EUA (POWERS, 2004, p. 39-40).

No imediato pós-guerra, os Estados Unidos viveram uma radicalização dos movimentos de esquerda devido aos desdobramentos da Revolução Russa. Imediatamente, o Departamento organizou uma ofensiva contra os considerados radicais, vetorizada pela recém-criada General Intelligence Division (GID) dentro do BOI, chefiada por J. Edgar Hoover. Os anos de 1919 e 1920 foram os anos chamados de Red Scare (Medo Vermelho), ao longo dos quais a GID e Hoover reprimiram fortemente as organizações de esquerda (HAGEDORN, 2007).

Desde aquela época, as atividades do Bureau e do DOJ eram questionadas por autoridades e pela população norte-americanas. O caso mais importante nesse sentido foi o afastamento do então attorney general, Harry M. Daugherty, em 1924, devido a um escândalo político de corrupção. Em seu lugar foi nomeado Harlan F. Stone, junto

\footnotetext{
${ }^{3}$ O Secret Service é uma agência do governo federal encarregada de proteger os principais líderes políticos dos Estados Unidos e salvaguardar as infraestruturas fundamentais do país. Foi fundado em 1865 ligado ao Department of Treasury, e na época tinha a função de investigar crimes como fraude de moeda e de terras públicas. Apenas no começo do século XX, o Secret Service passou a ter a função que tem hoje. Em 2003, foi integrado ao Department of Homeland Security.
} 
com a ascensão de Hoover à liderança do BOI. Após esses acontecimentos, as atividades investigativas passaram a ser mais focadas em casos criminais e no objetivo de reforçar a Lei Seca nos EUA, já que nesse momento o "ímpeto revolucionário" que marcara o país nos anos de 1919 e 1920 havia arrefecido.

Os anos 1930 foram marcados pela profissionalização do Bureau. Foi nesse decênio que a instituição criou o primeiro laboratório criminal e a sua academia de treinamento de agentes. Além disso, a partir de 1934 os agentes adquiriram a autoridade de realizar prisões e portar armas. Em 1935, o BOI mudou seu nome definitivamente para Federal Bureau of Investigation (FBI).

Também foi nesse período que o FBI passou a investir significativamente em sua imagem pública, com campanhas publicitárias nos jornais e no rádio e com envolvimento direto do Bureau na produção de vários roteiros de filmes de Hollywood com a temática policial, exaltando os agentes e a instituição (THEOHARIS, 2004, p. 41). A imagem institucional veiculada nesses meios foi a de um Bureau isento, apolítico e infalível, que sempre resolvia os casos e prendia os malfeitores.

Esse processo de crescimento do FBI esteve ligado ao governo de Franklin Delano Roosevelt (1933-1945), que aumentou significativamente o orçamento da instituição devido ao contexto de fortalecimento do governo federal com o New Deal ${ }^{4}$. Nesse momento, a propaganda veiculada em programas de rádio, filmes e quadrinhos foi bastante bem-sucedida. A figura do agente do FBI conseguiu espaço na cultura popular estadunidense e a instituição adquiriu poder e influência bastante significativos. Escorada nessa legitimidade pública, a agência passou a coletar informações pessoais de várias figuras políticas estadunidenses, bem como criar listas de subversivos a serem monitorados. A seletividade dessa vigilância era bastante clara: minorias (particularmente negros e homossexuais) eram alvo prioritário das investigações do Bureau (JEFFREYS-JONES, 2007, p. 155-156).

Durante a Segunda Guerra Mundial, o FBI realizou funções similares às do conflito mundial anterior. Entretanto, com a aliança dos EUA com a URSS, o presidente Roosevelt manteve o Bureau longe de investigações que pudessem desgastar

\footnotetext{
${ }^{4}$ Franklin Delano Roosevelt (1882-1945) foi o $32^{\circ}$ presidente dos Estados Unidos. Foi o responsável pelo New Deal, conjunto de experimentações econômicas aplicadas a partir de 1933 para tentar recuperar a economia norte-americana durante a Grande Depressão.
} 
as relações entre os dois países. Contando com o aval do presidente, o Bureau, em conjunto com órgãos militares de inteligência, criou um programa de coordenação de informações pertinentes ao conflito mundial. Couberam ao FBI as ações de espionagem e contraespionagem em âmbito doméstico (JEFFREYS-JONES, 2007, p. 114-117).

Com a morte de Roosevelt e o fim da guerra e da aliança com a URSS, o Bureau novamente concentrou suas atenções na investigação de comunistas dentro do território norte-americano. No âmbito repressivo de suas investigações, o Bureau começou um esforço de indexação dos membros do Partido Comunista dos Estados Unidos (CPUSA) para a adição a uma lista de subversivos (POWERS, 1998, p. 194-195).

O papel do FBI no início da Guerra Fria foi muito importante, aliando-se a dois dos mais expressivos nomes do anticomunismo nos EUA: os políticos republicanos Joseph McCarthy e Richard Nixon. O Bureau teve conexões com McCarthy durante os anos iniciais do período conhecido como macartismo, de extrema paranoia e vigilância a alegados comunistas (O’REILLY, 1983, p. 374). Em 1947, o diretor do FBI apareceu perante o HUAC (House Un-American Activities Committee) - do qual Nixon fazia parte - criticando a política governamental de contenção ao comunismo e advogando por medidas mais repressivas (POWERS, 2004, p. 210). Esse envolvimento na luta anticomunista se exacerbou nos anos 1950 e 1960, quando o FBI investigou muitas figuras públicas norte-americanas.

Em meados da década de 1950, com muitas de suas investigações frustradas por decisões do Departamento de Justiça ou da Suprema Corte, o FBI instituiu um novo programa secreto de investigações, o COINTELPRO (Counterintelligence Program). Inicialmente voltado para investigações de comunistas, o programa foi significativamente usado também contra ativistas negros, como Martin Luther King Jr. Em 1967, o Bureau iniciou uma seção específica do COINTELPRO para a atuação contra organizações negras radicais, como os Panteras Negras. Segundo um dos documentos do programa, o objetivo era "expor, romper, desviar, desacreditar ou então neutralizar as atividades de organizações e grupos de ódio nacionalistas negros, seus porta-vozes, membros e colaboradores, e combater sua propensão para a violência e a 
desordem civil" ${ }^{, 5}$.

A adesão tímida do governo de John F. Kennedy (1961-1963) às pautas dos Civil Rights contribuiu para a escalada da vigilância em relação ao movimento negro. Interessado em não perder o apoio dos democratas sulistas, adeptos da segregação racial, o presidente tentou não desagradá-los, ao mesmo tempo em que tentava frear as tensões raciais que se avolumavam ${ }^{6}$. O tema racial foi finalmente incorporado pelo projeto político de Kennedy, mas era do seu interesse que o movimento fosse controlado de perto, já que qualquer conexão entre Civil Rights e algum comunista poderia causar sérios danos à imagem do governo (O’REILLY, 1988, p. 202-205).

Com a morte de Kennedy em 1963 e a ascensão de Lyndon Baines Johnson (19631969) à presidência, estabeleceu-se um laço de profunda dependência entre o presidente e Hoover, já que o diretor só pôde se manter no cargo via decreto presidencial, por ter ultrapassado a idade de aposentadoria compulsória. Com isso, o FBI passou a ser diretamente utilizado por Johnson para investigar a oposição. O Bureau passou a coordenar com a Casa Branca a vigilância aos ativistas do movimento negro, opositores da Guerra do Vietnã, movimentos estudantis e até ao próprio Partido Democrata (THEOHARIS, 2004, p. 125-126).

Com o novo presidente, o reforço aos Civil Rights ganhou fôlego, sendo aprovados o Civil Rights Act, de 1964, e o Voting Rights Act, de 1965, resultados de anos de ativismo do movimento negro e apoio de parte da sociedade civil. ${ }^{7}$ Tais leis foram um duro golpe nas práticas segregacionistas no país, abrindo para que perspectivas

\footnotetext{
${ }^{5}$ Airtel de Hoover para SAC Albany, 25 de agosto de 1967. COINTELPRO Black Extremist File, Section 1, p. 1., Serial 100-4488006. Uma parte dos documentos do COINTELPRO podem ser consultados em < https://vault.fbi.gov/cointel-pro>. Acesso em: 26 set. 2020.

${ }^{6}$ Estamos nos referindo ao período circunscrito do Civil Rights, conhecido como fase clássica - entre 1954 e 1965 - , quando o movimento negro atuou de forma massiva e organizada no país, tendo obtido conquistas jurídicas e sociais importantes. Parte significativa da bibliografia recente sobre os Civil Rights defende que tal denominação se estenda aos movimentos negros pré-1954 e pós-1965, focando na ampliação da periodização, definindo-a como Long Civil Rights (HALL, 2005, pp. 1233-1263).

${ }^{7}$ O Civil Rights Act de 1964 tornou ilegal a discriminação baseada em raça, religião, gênero ou nacionalidade, e a segregação racial em registros de votantes e em espaços públicos e privados, ainda que o racismo, hoje considerado estrutural, tenha permanecido. O Voting Rights Act de 1965 garantiu o direito de voto à população negra norte-americana. Embora tecnicamente a Constituição dos Estados Unidos garantisse o voto a todos os cidadãos, várias leis segregacionistas impediam, na prática, que pessoas negras votassem. Criavam-se empecilhos para o registro de votantes - como deslocamento excessivo para os procedimentos burocráticos - ou até impedia-se que pessoas negras tivessem acesso às urnas, por meio de violência física. O Voting Rights Act atingiu juridicamente tais práticas, embora a execução do processo de integração dos negros por meio do voto tenha sido lenta.
} 
jurídicas fossem implementadas. A ilegalidade da discriminação racial e a garantia jurídica do direito ao voto, no entanto, não foram suficientes para incluir os afro-americanos na sociedade estadunidense: apesar da tardia conquista do voto, rapidamente o movimento notou que os negros continuavam como cidadãos de "segunda classe", em situação subalterna aos brancos. Procedimentos de segregação racial foram desenvolvidos em reação às vitórias do movimento negro, com a ampliação da suburbanização da classe média branca (MAY, 2017, pp. 57-96). Até os dias de hoje o direito ao voto para minorias é questão importante nos Estados Unidos, e novas práticas desafiam esses grupos a exercerem sua cidadania. ${ }^{8}$

Com essas novas leis, o FBI passou também a ser mais pressionado para investigar casos de violência contra a população afro-americana. Símbolo desse novo esforço foi a abertura de um novo escritório do Bureau na cidade de Jackson, no Misssissippi, em 1964. Tal episódio se deu por pressão popular após o sequestro e assassinato de três ativistas dos Civil Rights (dois negros e um branco) na cidade por parte de supremacistas brancos. Como a agência não tinha nenhum escritório no estado até aquele momento - e também em parte pelos interesses de uma parcela da comunidade local em atrasar os trabalhos —, a investigação foi extremamente lenta e ineficaz, fazendo com que o presidente e o diretor usassem a criação da nova unidade do Bureau para reforçar as relações públicas da instituição e reafirmar um compromisso (ao menos no discurso) com os casos que envolviam Civil Rights. (POWERS, 2004, p. 267)

Naquele momento o Bureau já dava sinais de enfraquecimento. O envelhecimento de Hoover e a dependência para com o presidente se tornaram fatores impeditivos para a manutenção da imagem pública e dos privilégios da instituição. A continuidade da vigilância e da repressão aos movimentos sociais começaram a cobrar

\footnotetext{
${ }^{8}$ Em 2013, a Suprema Corte dos Estados Unidos - no caso Shelby County v. Holder - aboliu alguns dos pontos do Voting Rights Act, diminuindo a supervisão federal às leis de voto estaduais. $\mathrm{O}$ argumento da maioria dos juízes foi que as condições sociais do país já eram diferentes das de 1965, e que a segregação já havia chegado ao fim. A consequência de tal decisão são novas leis que prejudicam o direito ao voto: em 2021, após inédita vitória do Partido Democrata na Georgia, o estado aprovou novas práticas que endurecem as políticas de registro de votantes e impedem o oferecimento de água e alimento nas longas e muitas vezes demoradas filas para as urnas. De acordo com os políticos conservadores responsáveis por essas novas leis, o fornecimento de quaisquer suprimentos nas filas constitui tentativa de "influenciar o voto". Tais limitações afetam desproporcionalmente os condados com maioria negra na população, que tem de enfrentar obstáculos maiores para votar. Ver $<$ https://www.nytimes.com/2021/03/25/us/politics/georgiavoting-law-republicans.html?>. Acesso em 02 abr. 2021.
} 
seu preço, com vários boatos circulando no Congresso e na imprensa sobre as escutas que o FBI usava para monitorar ativistas. Embora as escutas tivessem sido legalizadas em 1968, isso não impediu que o Bureau fosse fortemente questionado em suas atividades (JEFFREYS-JONES, 2007, p. 167).

A ascensão de Nixon no ano de 1969 permitiu, por parte do governo, a total falta de controle do FBI sobre suas próprias técnicas investigativas. O novo presidente republicano tratou logo de organizar o chamado Huston Plan, que se tratava basicamente da expansão nacional da vigilância a cidadãos norte-americanos, nos moldes do COINTELPRO do Bureau (THEOHARIS, 2004, pp. 127-8). Embora o plano não tenha sido levado a cabo, toda a movimentação do governo para fazê-lo foi sintomática da falta de força política por parte do diretor do FBI, que se opôs ao plano por saber que não haveria como manter o esforço em segredo da imprensa e da população.

Tendo falecido em 1972, o velho diretor John Edgar Hoover não viveu o bastante para ver sua instituição ser denunciada publicamente em meados dos anos 1970 pelos abusos cometidos. Em 1975, foi organizado pelo senado o Church Committee para investigar denúncias contra as principais agências de inteligência do país, o FBI, a CIA e a NSA ${ }^{9}$. Com isso, recomendou-se uma reforma que colocou fim à Era Hoover no Bureau.

\section{Acesso e censura: as fontes do FBI}

$\mathrm{O}$ acesso às fontes federais dos Estados Unidos é delimitado pelo Freedom of Information Act (FOIA), que entrou em vigor no país em 1966. Em 1974, a lei foi alterada para facilitar o acesso aos documentos do governo, especialmente os das agências de inteligência, permitindo trabalhos acadêmicos sobre várias das instituições governamentais norte-americanas (BUITRAGO e IMMERMAN, 1981, p. 33). Atualmente, o FOIA permite que se faça um requerimento online de qualquer documento cujo acesso seja permitido ${ }^{10}$.

\footnotetext{
${ }^{9}$ A Central Intelligence Agency (CIA) é uma agência federal norte-americana criada em 1947, encarregada da atividade de inteligência externa. A National Security Agency (NSA) é também uma agência federal, criada em 1952 e com funções de inteligência interna. É ligada ao U.S. Department of Defense (DOD).

${ }^{10} \mathrm{O}$ requerimento online pode ser feito em 〈https://efoia.fbi.gov/\#home>. Acesso em: 26 set. 2020.
} 
O acesso ao arquivo do Bureau, em particular, não é aberto ao público, sendo que o requerente deve solicitar os documentos por meio do FOIA e os agentes responsáveis pelo arquivo partem em busca dos escritos para disponibilização. Os originais não podem ser levados para fora da instituição, sendo disponibilizadas aos requerentes apenas cópias.

A possibilidade de obtenção dessas fontes não foi simplesmente aceita pelas instituições de inteligência, incluindo o FBI. Após a morte de Hoover, a agência tentou manter os abusos cometidos longe dos holofotes da mídia e do grande público, com recorrentes destruições de documentos. Vários tipos de obstáculos foram colocados aos que requisitaram acesso aos arquivos: taxação excessiva para a obtenção de cópias; buscas malfeitas ou incompletas por parte de funcionários do FBI nos arquivos e recusa em disponibilizar os documentos requisitados (BUITRAGO e IMMERMAN, 1981, p. $34)$.

Além disso, não é possível saber a amplitude real dos arquivos. A principal adversidade do pesquisador é que ninguém pode acessar pessoalmente os documentos, o que indica a grande dificuldade em trabalhar com essas fontes. Nesse sentido, estabelecer a integralidade de um conjunto de escritos é quase impossível, já que quase sempre algo foi destruído, proibido de ser acessado ou mesmo nunca descoberto (BUITRAGO e IMMERMAN, 1981, p. 104). Embora o trabalho pioneiro de Ann Mari Buitrago e Leon Andrew Immerman apresente as dificuldades de acesso e interpretação das fontes do FBI nos anos 1980, muitos desses problemas continuaram nos anos posteriores (POWERS, 2004, pp. 1-27; THEOHARIS, 2004, pp. 105-116).

Historiadores e pesquisadores do Bureau continuam com dificuldades na comunicação com a agência e não tendo acesso direto aos arquivos da instituição. Até hoje é comum que o FBI, em vez de fornecer os documentos das requisições online do FOIA, direcione requisitores para o FBI Vault, página na internet que contém uma série de documentações incompletas sobre casos famosos da agência ${ }^{11}$. As limitações desse site são enormes: apenas 216 das 16 mil páginas da investigação de Martin Luther King Jr. estão disponíveis lá. Por fim, muitas das fontes ainda são inacessíveis aos

\footnotetext{
${ }^{11} \mathrm{O}$ escritor Russ Kick relatou em seu site Memory Hole - uma das muitas iniciativas de arquivamento de documentos governamentais norte-americanos na internet - as dificuldades na obtenção dos arquivos da investigação de Martin Luther King Jr. até 2016. Ver $<$ http://thememoryhole2.org/blog/tag/Martin+Luther+King+Jr. $>$. Acesso em 01 abr. 2021. O FBI Vault pode ser acessado em <https://vault.fbi.gov/>. Acesso em 01 abr. 2021.
} 
pesquisadores. As transcrições das escutas utilizadas no inquérito de King, por exemplo, estão seladas até 2027, de acordo com decisão judicial de $1977^{12}$.

Para completar o quadro, o FOIA prevê uma série de mecanismos de supressão de informações nas fontes por meio de exemptions (isenções), ou seja, exceções à regra geral de acesso aos documentos públicos federais. A censura nas fontes se dá de duas formas: tarjas pretas em partes ou supressão de páginas inteiras. As categorias da censura podem ser consultadas na Tabela 1.

As regras que regem as censuras são utilizadas de forma bastante elástica pela instituição, estendendo a cobertura dessas exemptions para informações que não seriam passíveis de tarjas (BUITRAGO e IMMERMAN, 1981, pp. 49-70). No entanto, como um mesmo documento pode ser requisitado por diferentes pessoas e em momentos distintos, ele eventualmente também passa por diferentes censores, o que pode fazer com que certas informações sejam censuradas em um caso e não em outro.

Também é importante entendermos que o Bureau produzia diferentes tipos de escritos durante as investigações. Os distintos destinatários de cada escrito, bem como o grau de urgência de cada documento e a circulação à qual eram submetidos são importantes para entendermos de que modo a informação era circulada e categorizada pelos funcionários do Bureau. A partir do conhecimento desses diferentes suportes documentais, é possível vislumbrar que tipo de informação era disseminada, para quem e de que maneira. Indo além, a tipologia nos permite estabelecer as conexões entre as diferentes produções escritas da instituição, retraçando a maneira como uma mesma determinada informação foi sendo lapidada e modificada em diferentes escritos.

\footnotetext{
${ }^{12}$ Esses arquivos foram selados em 1977 após processo movido pela instituição fundada por King, a Southern Christian Leadership Conference (SCLC), contra o FBI em 1977. A organização buscava a liberação de toda a documentação da investigação do Bureau, mas o juíz John Lewis Smith Jr. decidiu pela entrega de todos os arquivos para o National Archives e pelo selamento das transcrições de escutas por 50 anos. Ver <https://www.nytimes.com/1977/02/01/archives/fbi-ordered-to-send-king-tapes-toarchives.html\#: :text=Martin\%20Luther\%20King\%20Jr.\%20to,until\%20his\%20death\%20in\%201968>. Acesso em 01 abr. 2021.
} 
Tabela 1 - Categorias de censura adotadas na documentação federal norteamericana

\begin{tabular}{|c|c|}
\hline Categorias & Informação Suprimida \\
\hline$b(1)$ & Informações relacionadas à segurança nacional \\
\hline$b(2)$ & Informações relacionadas ao funcionamento interno de uma agência \\
federal
\end{tabular}

Fonte: 〈https://vault.fbi.gov/explanation-of-exemptions>. Acesso em: 30 mai. 2021.

Vale ressaltar que, em geral, as fontes acessíveis do FBI consistem em escritos do/para o quartel-general. Infelizmente, os arquivos específicos dos escritórios regionais são de mais difícil acesso, o que de certa forma direciona o olhar do pesquisador 
inteiramente para a dinâmica e os funcionários do quartel-general em Washington D.C. ${ }^{13}$ No entanto, esses documentos são importantes para entendermos a circulação da informação, já que era a sede quem coordenava essa disseminação. Também só é possível entender a relação do FBI com outras instâncias governamentais a partir desses escritos, já que os escritórios regionais não podiam se comunicar diretamente com instituições de fora do Bureau (BUITRAGO e IMMERMAN, 1981, pp. 7 e 37).

O FBI produzia uma gama bastante variada de documentos nos anos 1950 e 1960, como podemos observar na tabela 2. Os Teletypes, por exemplo, continham informações que deveriam ser passadas rapidamente ao quartel-general, como itinerários de viagem dos investigados. Os Relatórios Resumidos (Summary Reports) continham seleções de elementos importantes de uma investigação ao longo de meses, sendo bastante extensos. Os Memorandos Letterhead eram a comunicação oficial do FBI com outras instâncias governamentais, sendo o canal oficial de disseminação de informações do Bureau. Os memorandos eram documentos internos ao quartel-general. Já os Airtels eram comunicações cotidianas entre a sede do Bureau e os escritórios regionais, relacionadas aos inquéritos.

${ }^{13}$ Os escritórios regionais eram os responsáveis pela condução das investigações de acordo com suas jurisdições territoriais, sob a supervisão apropriada do quartel-general. Geralmente se encontravam nas grandes cidades de cada estado, como Nova York, Los Angeles, Detroit, e outras. 
Tabela 2 - Tipos de documentos do FBI

\begin{tabular}{|c|c|c|c|c|}
\hline $\begin{array}{c}\text { Tipos de } \\
\text { documentos }\end{array}$ & Circulação & $\begin{array}{c}\text { Tamanho } \\
\text { (páginas) }\end{array}$ & Autores & Destinatários \\
\hline Airtel & $\begin{array}{c}\text { Interna ao } \\
\text { FBI }\end{array}$ & De 1 a 3 & $\begin{array}{c}\text { Escritórios } \\
\text { Regionais (ER) }\end{array}$ & $\begin{array}{c}\text { Quartel-General } \\
\text { (QG) }\end{array}$ \\
\hline Memorando & $\begin{array}{c}\text { Interna ao } \\
\text { FBI }\end{array}$ & De 1 a 3 & $\begin{array}{r}\text { Quartel General } \\
(\mathrm{QG})\end{array}$ & $\begin{array}{c}\text { Escritórios } \\
\text { Regionais (ER) }\end{array}$ \\
\hline Letterhead & $\begin{array}{c}\text { Externa ao } \\
\text { FBI }\end{array}$ & De 1 a 5 & ER ou QG & ER ou QG \\
\hline $\begin{array}{c}\text { Teletype } \\
\text { Resumidos }\end{array}$ & $\begin{array}{c}\text { Interna ao } \\
\text { FBI }\end{array}$ & De 1 a 3 & ER ou QG & ER ou QG \\
\hline
\end{tabular}

Fonte: feita pelo próprio autor.

As diferenças entre os documentos não são questão apenas burocráticas. A linguagem de cada escrito, por exemplo, diferia sensivelmente de um para o outro. Os memorandos internos ao quartel-general geralmente tinham julgamentos morais mais explícitos que os airtels cotidianos ou os Letterheads formais enviados ao DOJ. Essa diversidade tipológica permitiu ao Bureau veicular e disseminar informações (e preconceitos) sem comprometer sua imagem pública. A bibliografia sobre o FBI em geral não levou em conta esse tipo de diversidade documental. Por seu caráter primordialmente descritivo, historiadores buscaram construir narrativas coerentes a partir de informações que obtinham desses escritos (GARROW, 1988, p. 9). Produziu-se, dessa forma, uma "planificação" dos documentos e de seus conteúdos, levando-os em conta como se fossem todos a mesma coisa. No entanto, para realizar uma leitura crítica desses escritos, devese levar em conta sua diversidade tipológica e problematizar seu conteúdo. 
A confiabilidade das fontes e a representação dos investigados: o caso Martin Luther King Jr.

Obviamente, qualquer documento histórico deve ser levado em conta com um certo grau de ceticismo e crítica, mas poderia uma instituição com tanto poder de vigilância veicular informações erradas em seus documentos? Seja por limitações técnicas ou erro humano, seja por interesses políticos, as fontes do FBI apresentam sim informações falsas e erros.

Primeiramente, devemos levar em conta o grau de sofisticação tecnológica do Bureau até os anos 1970. Embora em muitas instâncias a agência fosse de fato uma vanguarda científica da polícia no país, ainda assim seus meios eram bastante restritos. Nesse sentido, as informações veiculadas nos documentos apareciam muitas vezes de forma limitada e não confiável. No prefácio do livro de Buitrago e Immerman sobre a documentação do FBI, a escritora Jessica Mitford relatou um episódio curioso relacionado à investigação de seu marido:

\footnotetext{
Eu notei um certo relaxamento por parte das agências que tomaram para si a tarefa de investigar-nos, os subversivos. Por exemplo, meu marido, Robert Treufhaft, finalmente conseguiu (após os usuais anos de esforço) algumas páginas soltas do que foi alegado ser seu dossiê completo, tanto do FBI quanto da CIA. Na "Descrição do Investigado", o FBI dizia: "1,73m, robusto, careca". A CIA dizia: “1,78m, cabelo preto, esguio". Ora! É fácil dizer qual agência o Bob acha mais confiável. (BUITRAGO e IMMERMAN, 1981, p. i) ${ }^{14}$
}

Embora cômico, o relato da escritora mostra como as dificuldades das investigações eram significativas. Informações errôneas sobre instituições investigadas, demora em reconhecer pessoas em fotos tiradas por agentes, relatos desencontrados e contraditórios, todos esses elementos eram comuns nos documentos do FBI. Isso levanta a questão da confiabilidade das fontes do Bureau. Afinal, é possível confiar nesses documentos?

Essa questão adquiriu contornos bastante contemporâneos recentemente, com uma polêmica entre os historiadores David Garrow e Barbara Ransby. Ao analisar novos documentos da investigação que o FBI fez de Martin Luther King Jr. entre 1962 e 1968,

\footnotetext{
${ }^{14}$ Todos os excertos advindos de textos em inglês foram traduzidos pelo autor.
} 
o autor publicou um artigo sobre o pastor na revista Standpoint. Entre as informações novas presentes nos documentos consultados por Garrow, a mais chocante foi uma alegada omissão, por parte do ativista, em relação a um estupro cometido por um colega dos Civil Rights. A fonte - um escrito do FBI que consiste em suposta transcrição de escuta colocada em quarto de hotel frequentado por King - relata que um grupo se encontrou naquele local e "discutiu quais mulheres entre as da paróquia seriam adequadas para atos de sexo natural ou não-natural. Quando uma das mulheres protestou, dizendo que não aprovava isso, um dos pastores imediatamente a estuprou de forma forçada" (GARROW, 2019). Em uma marcação feita à mão ao lado das palavras digitadas, lê-se que "King olhou, riu e ofereceu conselhos" (GARROW, 2019).

Segundo Garrow, caso comprovado, esse episódio colocaria em dúvida o legado de Martin Luther King Jr. como um dos principais ativistas negros de sua época. No entanto, a análise do autor é bastante problemática. A questão do alegado estupro aparece apenas em um dos parágrafos do artigo do historiador, sendo boa parte dele dedicada a uma narração bastante gráfica de outros episódios sobre a vida sexual de King, uma alegada filha ilegítima do pastor e problemas dele com seus impostos. Em nenhum momento Garrow questionou a veracidade das informações, a confiabilidade dos documentos ou o fato de informação tão impactante vir à tona simplesmente a partir de uma anotação feita à mão na margem de um escrito do FBI por alguém desconhecido. Nesse sentido, a informação poderia ser falsa e mesmo assim foi relatada pelo historiador.

Em resposta, as críticas da historiadora Barbara Ransby (publicadas no New York Times) a Garrow foram bastante contundentes. Segundo ela, vários estudiosos já afirmaram anteriormente que King teve uma vida sexual fora do casamento e que tinha um apreço excessivo por bebidas alcóolicas. No entanto,

(...) o ensaio de David Garrow publicado na Standpoint, uma revista britânica conservadora - vai muito além, fazendo a séria alegação de que King pode ter testemunhado e encorajado um estupro. Absolutamente todas as alegações de estupro devem ser levadas a sério. No entanto, essa afirmação irresponsável, retirada de documentos questionáveis, tem sérias falhas e tende a transformar os leitores em fofoqueiros históricos ao adereçar o que consiste em pouco mais que rumor e insinuação dos arquivos do FBI. (RANSBY, 2019)

Segundo a historiadora, um elemento fundamental ausente no artigo de Garrow é o interesse do Bureau em sabotar a figura pública de Martin Luther King Jr. Assim como 
já dissemos anteriormente, a autora também questiona o detalhismo e as descrições extremamente gráficas de Garrow sobre a vida sexual do pastor. De acordo com ela,

\begin{abstract}
As narrativas sexuais gratuitas e lúgubres que o Sr. Garrow refaz dos documentos editados do FBI são reminiscentes do modo racista em que a sexualidade negra foi escrita historicamente: insaciável e, como o FBI escreveu três vezes, "não-natural". A chamada do ensaio descreve o Dr. King como um "libertino", capaz de sexo selvagem e fala rude. O quadro mais geral do ensaio, como o Dr. Garrow o constrói, sugere ao leitor que talvez seja possível que esse proponente da não-violência "olhou, riu e ofereceu conselhos" enquanto um de seus amigos, um pastor de Baltimore, "forçosamente estuprou" uma das mulheres de sua paróquia num hotel em Washington em 1964. (RANSBY, 2019)
\end{abstract}

Consideramos que as afirmações de Garrow constituem uma reprodução acrítica da documentação que ele consultou. Reafirmar e sublinhar a vida sexual do pastor, bem como mobilizá-la a determinados leitores, era justamente a lógica de uma parte importante da investigação do FBI. O objetivo de algumas das figuras que compunham o alto escalão do Bureau era expor King publicamente e, de forma clandestina, minar seu apoio entre a população norte-americana.

A vida sexual de King foi instrumentalizada constantemente pela instituição para sabotá-lo. O episódio mais famoso desse esforço foi o envio, por parte do FBI, de uma carta anônima para o pastor e sua esposa, tentando incitá-lo ao suicídio na época em que ele havia sido nomeado para o prêmio Nobel ${ }^{15}$. Juntamente com a carta, uma fita foi enviada contendo áudios de escutas usadas contra ele, que mostravam alegados encontros sexuais de King com prostitutas.

15 A carta pode ser lida na íntegra em: <https://www.nytimes.com/2014/11/16/magazine/what-anuncensored-letter-to-mlk-reveals.html>. Acesso em: 31 mar. 2021. 


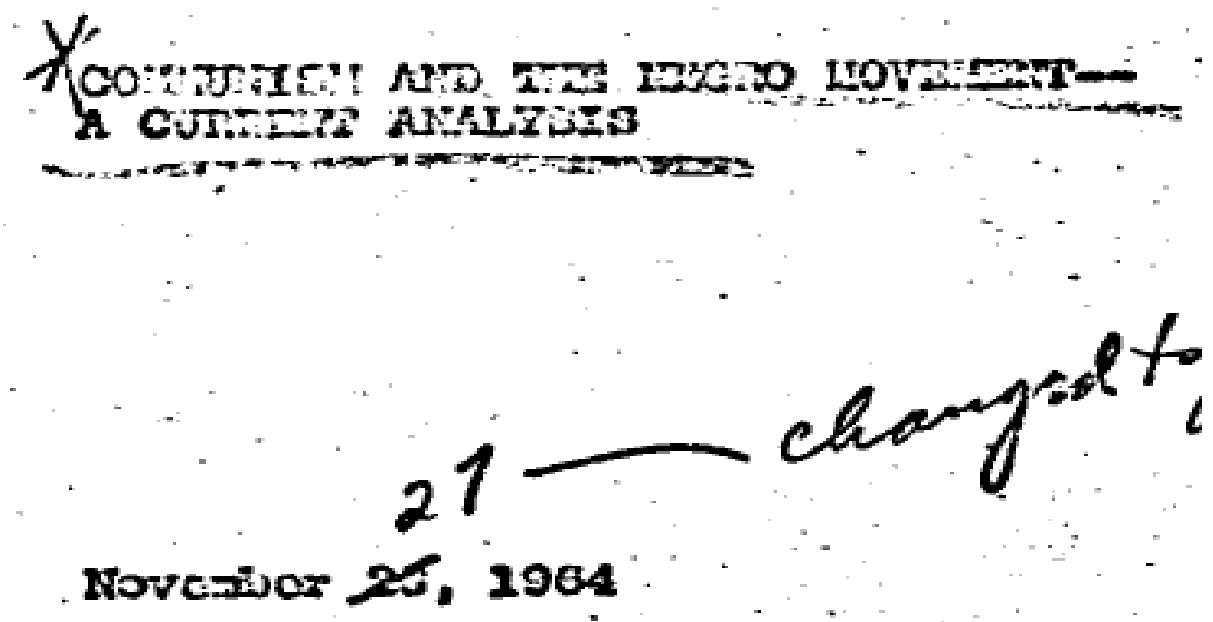

Fonte: Memorando de Cartha DeLoach para John P. Mohr, 7 de dezembro de 1964, Section 21, Martin Luther King Jr. FBI File.

No entanto, essas informações não foram utilizadas apenas para prejudicar seu casamento. A partir de 1963, foi produzida uma monografia chamada Communism and the Negro Movement - A Current Analysis, contendo informações sobre uma alegada influência comunista no movimento negro. Ela foi rapidamente tirada de circulação no mesmo ano, mas sua segunda versão, do ano seguinte, circulou significativamente nos círculos governamentais norte-americanos.

Essa monografia continha vários tópicos relacionados a King, ressaltando suas “conexões comunistas" e sua "conduta pessoal”. O conteúdo de tal escrito era tão sensível que foi classificado como top secret, indicando a circulação mais restrita possível para um documento do governo. Em 1967, o documento passou a ser disseminado para determinadas instituições nas quais King faria palestras ou participaria de eventos, como o Departamento de Agricultura ${ }^{16}$. O interesse crescente na figura do pastor, aliado ao seu ativismo cada vez mais incisivo ao fim da vida - principalmente contra a Guerra do Vietnã - geraram interesse nas informações contidas em tal monografia.

\footnotetext{
${ }^{16}$ Memorando de Alex Rosen para Cartha Deloach, 28 de fevereiro de 1967, Section 67, Martin Luther King Jr. FBI File.
} 


\section{Imagem 2 - Capa da terceira versão da monografia}

\section{C: CO:MUNIST INFLUENCE IN RACIAL MATTERS-- : $4:$ A CURRENT ANALYSIS}

\section{Po: April 10, 1967}

Fonte: Memorando de Hoover para o attorney general, 10 de abril de 1967, Section 88, Martin Luther King Jr. FBI File.

Como resultado, ela foi atualizada para incluir conteúdo sobre seu ativismo antiguerra. Surgiu assim, em 1967, a monografia Communist Influence in Racial Matters a Current Analysis, também classificada como top secret. Tal escrito foi amplamente circulado entre membros das mais diversas instâncias governamentais, como o comandante do Marine Corps, Wallace M. Greene Jr., e o Secretary of Labor, W. Willard Wirtz $^{17}$.

Em fevereiro de 1968, sugeriu-se que a monografia fosse novamente atualizada, devido ao Washington Spring Project (WSP) — organizado por King e outros ativistas —, que visava à luta por justiça econômica, com foco no combate à pobreza no país ${ }^{18}$. De acordo com documento de um membro da alta hierarquia da instituição, a atualização do escrito e sua disseminação serviriam "para fazer funcionários da alta hierarquia do

\footnotetext{
${ }^{17}$ Memorando de D. J. Brennan Jr. para William C. Sullivan, 30 de agosto de 1967, Section 75, Martin Luther King Jr. FBI File. O Marine Corps é o corpo de fuzileiros navais da Marinha estadunidense.

${ }^{18} \mathrm{O}$ WSP foi um projeto de mobilização em massa inspirado na Marcha sobre Washington por Trabalho e Liberdade, de 1963. Foi organizado por Martin Luther King Jr. e pela SCLC, mas o pastor foi assassinado em 4 de abril de 1968, antes dos protestos ocorrerem. O esforço foi reorganizado após a morte de King, sob o nome de Poor People's Campaign, e resultou em vários protestos na capital do país entre maio e junho de 1968. Entre as pautas do movimento estavam a luta por melhores condições econômicas para minorias e a diminuição da desigualdade.
} 
governo relembrarem do caráter vergonhoso de King"19. Com isso, a última versão da monografia foi produzida com o nome Martin Luther King, Jr., A Current Analysis.

Focando dessa vez apenas no ativista, o documento continha informações que não haviam sido publicadas anteriormente nas outras versões, particularmente detalhes sobre sua vida sexual e relações entre seu ativismo antiguerra e o comunismo, como podemos ver na imagem anterior, retirada do índice da monografia. Esse escrito também foi submetido a uma classificação menos restrita, Secret, indicando que deveria ser circulado mais amplamente. De acordo com memorando de março de 1968, ela "foi bem recebida na comunidade de inteligência", o que fez com que ela fosse considerada "útil para outras agências governamentais com responsabilidades de inteligência". O documento terminava recomendando que cópias da monografia fossem fornecidas para a Central Intelligence Agency (CIA), o Secretary of State Dean Rusk, os Joint Chiefs of Staff, o major-general Carl C. Turner, o Provost Marshal do exército, o general Leonard E. Chapman e para o comandante dos Mariners $^{20}$.

\footnotetext{
${ }^{19}$ Memorando de G. C. Moore para William C. Sullivan, 29 de fevereiro de 1968, Section 79, Martin Luther King Jr. FBI File.

${ }^{20}$ Memorando de G. C. Moore para William C. Sullivan, 19 de março de 1968, Section 79, Martin Luther King Jr. FBI File. Os Joint Chiefs of Staff (JCS) são o conjunto de oficiais seniores das forças armadas estadunidenses dentro do U.S. Department of Defense. A função do JCS é aconselhar o secretário de defesa, o presidente dos Estados Unidos e instituições federais do país em questões militares. No Brasil seria o equivalente ao Estado Maior Conjunto das Forças Armadas, órgão do Ministério da Defesa. O Provost Marshall era um cargo no exército norte-americano relacionado a investigações internas de membros da U.S. Army. Tal posto foi extinto após a Guerra do Vietnã e retomado em 2003, dessa vez como Provost Marshall General, cargo responsável pela chefia da Military Police Corps, o braço investigativo interno do exército estadunidense.
} 
Imagem 3 - Capa e parte do sumário da quarta versão da monografia

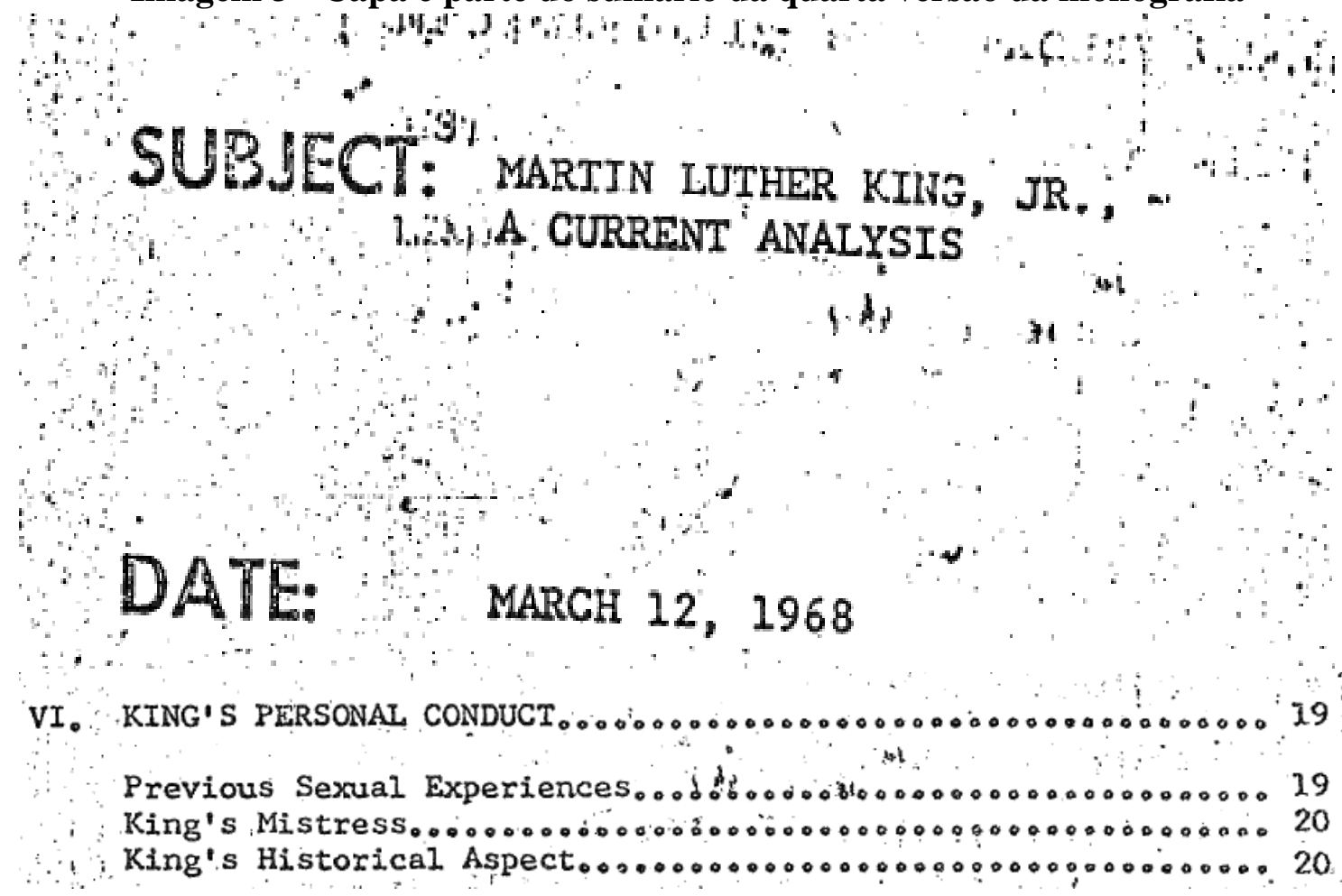

Fonte: memorando de G. C. Moore para William C. Sullivan, 11 de março de 1968, Section 85, Martin

Luther King Jr. FBI File.

A interpretação e a análise das documentações de inteligência devem, portanto, passar necessariamente por um ceticismo em relação às afirmações que são feitas sobre os investigados, já que respondem a determinados interesses de quem as produz. Uma investigação de inteligência, por ter caráter preventivo e não depender de um crime para ser iniciada (PACCI, 2002, p. 15), pressupõe a descrição de um investigado a partir de uma lógica de suspeição contínua (MAGALHÃES, 1997). Num contexto de Guerra Fria, a paranoia anticomunista e os diversos preconceitos reproduzidos por uma agência como o FBI desempenharam papel fundamental em representações falsas sobre os vigiados. Dessa forma, era de interesse de uma agência como o Bureau representar um investigado considerado perigoso (King) como um depravado sexual, o que teria a potencialidade de comprometer a figura pública do pastor.

Por meio de narrativas que ressaltavam a isenção política de seus funcionários, as agências de inteligência produziam - e ainda produzem - estereótipos relacionados aos investigados, classificando-os como "vilões" e "traidores", ao mesmo tempo que se 
afirmam como "especialistas" apolíticos (FICO, 2001, p. 218). Infelizmente, a leitura crítica dos documentos de inteligência não é sempre a tônica dos trabalhos que utilizam de fontes do FBI, muitas vezes reproduzindo e naturalizando as atividades da agência (BALL e BURROUGHS, 2012, posições 626, 642 e 1575). Ao utilizar essas fontes, portanto, o historiador deve atentar criticamente para os processos de produção e circulação de representações sobre os investigados.

Em seu artigo sobre arquivos de polícias políticas, a historiadora Ana Maria Camargo comentou sobre os documentos de regimes repressivos e como eles reproduzem os valores que sustentam seu próprio sistema político:

\begin{abstract}
Nos arquivos da polícia política predominam(...) informações nominativas, isto é, apreciações ou julgamentos de valor sobre pessoas explicitamente designadas. E as informações de caráter pessoal encontradas nos serviços de segurança são muitas vezes improcedentes, inexatas e enganadoras, como afirmou Raymond Frank Grover em amplo debate sobre o assunto. (CAMARGO, 1996, pp. 2-3)
\end{abstract}

Com isso, os "julgamentos de valor" são parte fundamental dos escritos do Bureau, assim como de qualquer outra agência de inteligência. O FBI de Hoover afirmava incessantemente ser uma instituição isenta politicamente e representante da moralidade, ao mesmo tempo que desrespeitava boa parte das diretrizes legais que deveriam controlar seu funcionamento. Por ter esses elementos subjetivos mais claros e evidentes, o trabalho de inteligência é sujeito a sérias limitações no que tange à análise das informações. De acordo com Loch K. Johnson,

A grande frustração da inteligência estratégica é que raramente se opera em um ambiente de total transparência. Ao invés disso, o mundo está repleto de incertezas, e, como resultado disso, lacunas de inteligência são inevitáveis e às vezes resultam em falhas por parte dos oficiais de inteligência em prover avisos robustos e oportunos de perigo. (...) Às vezes as falhas de inteligência são resultado de peças perdidas do quebra-cabeça. Às vezes, no entanto, os erros são fruto da inabilidade de indivíduos em analisar precisamente o significado das peças disponíveis, julgando inapropriadamente seus significados. (JOHNSON, 2007, p. 3) 
Ou seja, a análise e interpretação das informações coletadas estão sujeitas aos valores e limitações dos funcionários que as analisam e interpretam, bem como aos projetos das instituições por trás desses indivíduos. Sob essa ótica, é possível entender justamente os filtros de interpretação e seus desdobramentos nas investigações do FBI. Nesse sentido, só podemos mapeá-los a partir da análise e circulação do conhecimento dos agentes. O sentido dos escritos não se dá apenas singularmente em cada documento produzido, mas com uma "coleção exaustiva de informação" (JOHNSON, 2007, p. 3). Essa coleção, por sua vez, é organizada em um arquivo, elemento que sugere potencialidades e limitações em sua análise, e deve ser alvo de cuidados e considerações metodológicas por parte do historiador.

\section{Arquivos de inteligência: poder e representação}

Consideramos, primeiramente, que o arquivo é um "conjunto articulado de documentos que se acumulam, de forma natural e necessária, em razão do funcionamento de um organismo qualquer" (CAMARGO, 1996, p. 10). No entanto, o arquivo, sua organização e funcionamento não são neutros (ROBERTSON, 2006, p. 70). Assim como o documento, os agentes e a própria investigação, o arquivo é também uma expressão de determinadas relações de poder e influência, bem como de projetos políticos. Assim, é importante separar a intencionalidade do documento escrito da potencialidade analítica que ele possui. No caso dos arquivos, em geral, e das fontes relacionadas às investigações de inteligência, em particular, o que é escrito sobrepõe uma vontade de remeter de forma clara ao que é real, já que parte do fazer investigativo desse tipo é direcionar futuras ações em relação aos investigados. Segundo Ana Maria Camargo,

\footnotetext{
O documento de arquivo é a exteriorização de uma ação que se faz e refaz por efeito da força probatória que lhe é peculiar. E essa força depende, em larga medida, de mecanismos que acentuam sua capacidade de remissão direta à realidade, a ponto de formar com ela uma aliança indissociável. (CAMARGO, 1996, p. 6)
}

Assim, a legitimidade desses tipos de documentos se estrutura a partir dessa pretensa descrição fiel da realidade. A imagem institucional criada pelo Bureau - a de uma agência dita científica, isenta e eficiente - certamente contém essa tentativa de "remissão direta à realidade". Afinal, como poderia uma agência com tanto poder de 
vigilância não descrever de forma autêntica o que aconteceu? O papel do historiador, nesse sentido, é problematizar tanto a narrativa produzida pela instituição sobre si mesma, como também estabelecer um olhar crítico aos documentos escritos pelos funcionários da agência.

É fundamental, portanto, entender que os documentos não são encaminhados para o arquivo aleatoriamente. São enviados para lá por determinadas pessoas, organizados internamente segundo critérios pré-estabelecidos, categorizados de acordo com determinadas diretrizes e submetidos aos devidos processos burocráticos. Dessa forma, os escritos arquivados e os processos que os colocam em movimento expressam interesses, mecanismos institucionais de funcionamento e as condições de produção e circulação típicas da instituição de origem (CAMARGO, 1996, pp. 8 e 9).

Por meio de mecanismos de arquivo, uma investigação de inteligência produz sentido em relação ao(s) investigado(s). As classificações, as categorias, as descrições e a circulação dos documentos constroem representações múltiplas e, por vezes, contraditórias sobre uma mesma pessoa. Para o historiador francês François Hartog, a representação é uma tradução do Outro a partir de uma retórica de alteridade (HARTOG, 1999, pp. 30, 39 e 50). Ou seja, a representação envolve tanto a observação e a descrição acerca do representado, quanto a própria maneira de pensar de quem representa. Complementarmente, Roger Chartier afirma que as representações não são fruto da imaginação, mas sim elementos que mobilizam ações e interesses de grupo, tendo assim um impacto na realidade (CHARTIER, 1988, pp. 16-28).

É possível afirmar que o FBI — instituição marcada por um histórico de anticomunismo e racismo - construía imagens de ativistas negros como comunistas, simpatizantes do comunismo ou influenciados por bolcheviques, mesmo quando essa associação não era verdadeira. As categorizações que o Bureau usava nessas investigações cumpriam parte significativa nessas representações. Utilizava-se o número serial "100" para classificar tais inquéritos, que remetia à categoria de "Segurança Doméstica", assim como nas investigações de comunistas. Por outro lado, grupos como a Ku Klux Klan eram classificados como "157”, ou "Inquietação Civil” (HAINES e LANGBART, 1993, pp. 99-102 e 150). Essas representações não estavam, portanto, apartadas das relações de poder e do racismo que se expressava na sociedade. Militantes 
pacifistas negros eram considerados questão de segurança, enquanto supremacistas brancos não eram vistos como um grande perigo pelo Bureau (O'REILLY, 1991, p. 198 e 225).

Novamente podemos usar o caso King como exemplo. Em memorando de 1964 reproduzido aqui, escrito por um funcionário da Divisão de Segurança Doméstica da instituição, foi relatada uma reunião entre membros do governo e do Bureau para "explorar como melhor desenvolver nossa investigação do caso para produzir os resultados desejados sem prejudicar o Bureau. Analisamos de forma completa os meios de abordagem visando neutralizar Martin Luther King Jr. como um líder negro efetivo". O relato continuava, falando sobre possíveis maneiras de explorar a situação financeira da organização chefiada pelo pastor, a Southern Christian Leadership Conference (SCLC).

Imagem 4 - Documento relatando reunião entre altos funcionários do FBI sobre

Martin Luther King Jr.

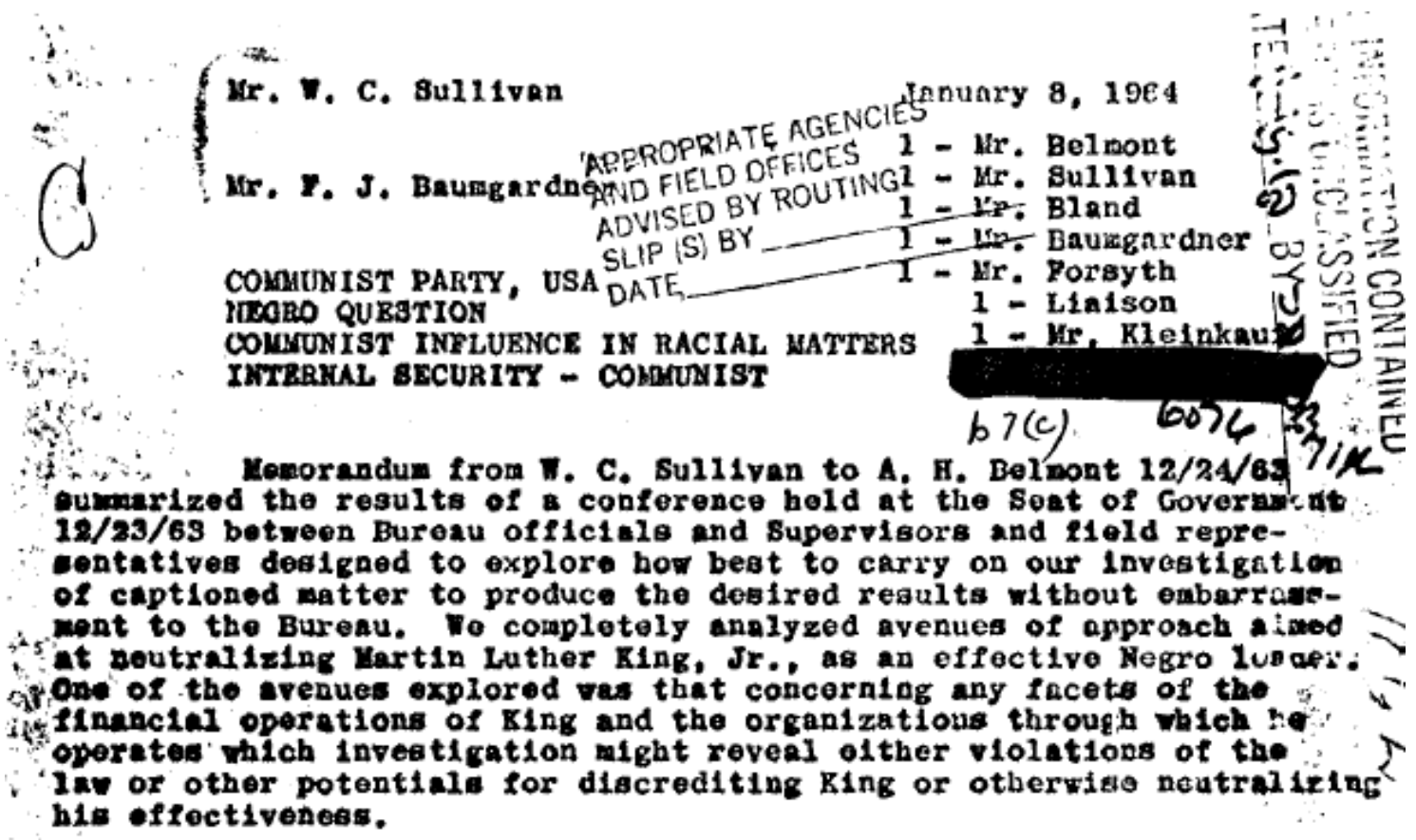

Fonte: memorando de F. J. Baumgardner para William C. Sullivan, 8 de janeiro de 1964, Section 7,

Martin Luther King Jr. FBI File. 
As conexões pessoais do ativista também eram exploradas nesse propósito, ressaltando-se qualquer indício de "influência comunista". Em um escrito de Hoover para o chefe do escritório de Nova York do Bureau, datado de 1964 e reproduzido a seguir, o diretor incitava os funcionários do FBI a obterem mais informações sobre as conexões de King com Bayard Rustin, um militante negro ex-comunista e homossexual, visando ao "potencial para o Bureau neutralizar a influência de King por causa das conexões comunistas que ele possui”.

Imagem 5 -Excerto de documento relatando a relação entre Martin Luther King Jr. e Bayard Rustin

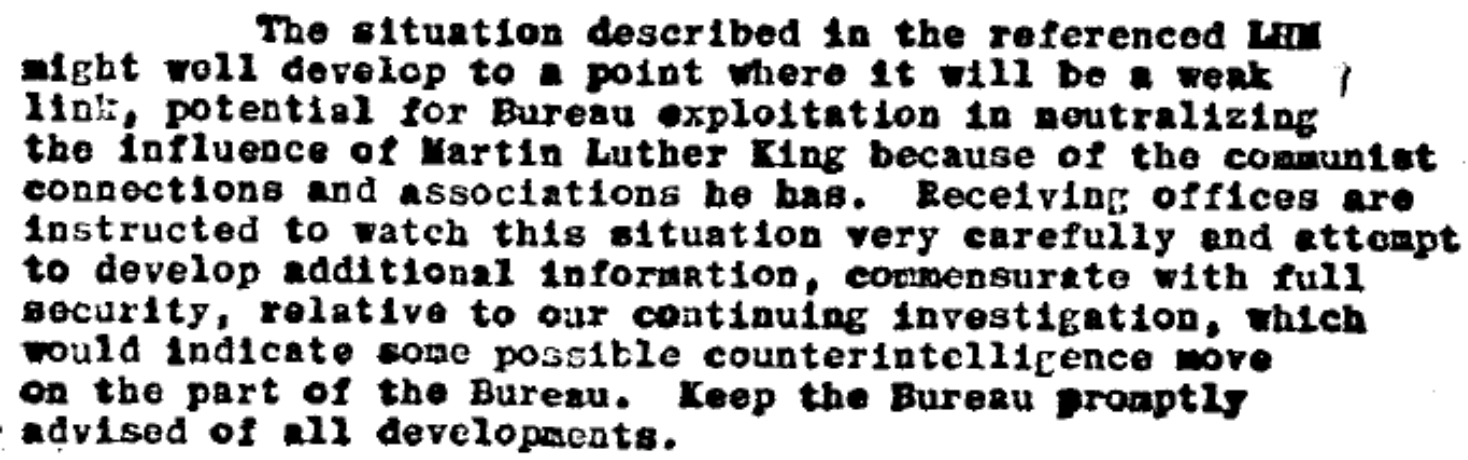

Fonte: Airtel de Hoover para o Special Agent in Charge (SAC) de Nova York, 19 de março de 1964, Section 10, Martin Luther King Jr. FBI File.

Dessa forma, as informações obtidas eram interpretadas de acordo com um objetivo claro: neutralizar o investigado, expondo uma pretensa "influência comunista" que incidia sobre ele. Esses documentos circulavam, como vimos, por amplos setores do governo norte-americano, influenciando opiniões de altos funcionários federais e exercendo um determinado poder sobre as visões que esses indivíduos tinham sobre King.

Falando sobre as mudanças em relação às interpretações sobre os arquivos na década de 1990, Isabel Travancas afirma que

(...) o arquivo passaria a ser visto como instância na qual se constroem "fatos" e "verdades". Esse novo estatuto teórico dos arquivos deve muito a alguns textos de Michel Foucault e Jacques Derrida. De maneira muito geral, podemos dizer que esses textos instituíram o "arquivo" como metáfora do cruzamento entre memória, saber e poder; como constructo político que produz e controla a informação, orientando a lembrança e o esquecimento (...) (TRAVANCAS, 2013, p. 68) 
A partir dessa perspectiva do arquivo como "metáfora do cruzamento entre memória, saber e poder", temos uma abordagem privilegiada para entender a produção documental do FBI. Os escritos do Bureau, nesse sentido, podem ser também considerados como expressão de um saber e de um poder, com o objetivo de mobilizar e construir uma determinada memória, seja sobre si mesmo, seja sobre os investigados. Ao mesmo tempo, a estima pública da instituição conferia um efeito de verdade às interpretações dos agentes acerca dos investigados, não importando quão equivocadas elas fossem. Sobre essa relação de poder e saber, uma consideração de Foucault é bastante útil:

(...) o poder, quando se exerce em seus mecanismos finos, não pode fazê-lo sem a formação, a organização e sem pôr em circulação um saber, ou melhor, aparelhos de saber que não são acompanhamentos ou edifícios ideológicos. (FOUCAULT, 2010, pp. 29-30)

O FBI, ao investigar seus alvos, colocava em circulação um determinado saber sobre eles, com as informações sendo estrategicamente mobilizadas de acordo com os interesses de Hoover e da alta hierarquia da instituição. Esse exercício se relacionava diretamente com a imagem institucional construída pelo Bureau. Sob a lógica da agência, apenas uma organização pretensamente isenta, apolítica, profissional e eficiente poderia coletar, organizar e disseminar o tipo de informação sensível com a qual lidava. Ao fazêlo, o FBI não só se afirmava a partir de seus valores autoproclamados, como também expressava os elementos que mantinham a instituição com as estimas governamental e pública necessárias para manter-se em sua atividade.

Mas como isso se materializava no fazer investigativo do FBI? Sobre a construção dos arquivos do sistema central do Bureau, Buitrago e Immerman afirmam que

Os arquivos "principais" do Sistema Central são construídos através das decisões do FBI (normalmente dos escritórios regionais) de iniciar investigações preliminares ou permanentes, baseadas em informações recebidas. Essas informações provavelmente foram geradas no curso de investigações já existentes e vieram de um informante, vigilância eletrônica (escuta) ou da polícia local. (BUITRAGO e IMMERMAN, 1981, pp. 4-5) 
Percebe-se que essas investigações tinham sua origem naquilo que estruturava as decisões do FBI: as informações recebidas. Esse elemento por si só já revela problemas, na medida em que uma informação não é necessariamente verídica. Dependendo da situação, uma informação pode ter sido falsificada, plantada ou lapidada de acordo com determinados interesses. Mesmo no caso de uma informação "verdadeira", poder-se-ia argumentar que determinados valores, pessoais ou institucionais, poderiam influenciar o estabelecimento de uma investigação ou não. Nesse caso, elementos como o racismo e o anticomunismo expressos pela instituição tiveram grande influência no estabelecimento de investigações contra figuras negras e/ou de esquerda nos Estados Unidos e na maior intensidade que esses inquéritos tinham em relação a outros.

A decisão dos escritórios regionais em abrir uma investigação, por sua vez, expressava outras relações de poder na obtenção da informação, na medida em que revelava uma significativa autonomia funcional desses escritórios em relação ao quartelgeneral. Dessa forma, a capacidade de instalar escutas, de recrutar informantes e de estabelecer contatos com as polícias locais não só sustentavam, de forma autêntica ou não, a decisão de iniciar um inquérito, como também geravam um fluxo de investigações que se retroalimentava: a partir de um inquérito específico, outros poderiam ser criados.

Nos mecanismos de arquivo esse poder também se expressava. O caso de algumas técnicas de circulação de informação, como as administrative pages (páginas administrativas), são bastante elucidativas. Essas páginas eram folhas que deveriam ser destacadas dos documentos e mantidas pelos oficiais da alta hierarquia do Bureau. As informações contidas nessas páginas eram geralmente mais sensíveis, e a gestão informacional envolvendo-as é bastante interessante. Segundo Athan Theoharis,

Ao falar sobre esse novo requisito de relatórios [páginas administrativas], Hoover citou sete exemplos de informação a serem reportados em páginas administrativas. O primeiro envolvia alegações de que "A...é um membro do Partido Comunista e, além disso, A é um homem de moral duvidosa, um bêbado vivendo com uma prostituta conhecida...A alegação de pertencimento ao Partido Comunista deve ser colocada na seção investigativa, enquanto que a alegação de moral duvidosa deve ser incluída na seção administrativa". (THEOHARIS, 2004, p. 111) 
Ou seja, informações sobre subversão poderiam ser dispostas no corpo do escrito, mas o que concernia à moralidade deveria ser de conhecimento exclusivo da alta hierarquia da instituição. Certos conhecimentos, portanto, estavam sujeitos à disseminação, enquanto outros ao segredo. A circulação livre de informações como "bêbado" ou "vive com uma prostituta conhecida" poderia prejudicar o próprio Bureau, na medida em que exporia o trabalho da instituição e suas preocupações com aspectos da vida privada dos investigados. Elementos como a subversão, por outro lado, eram facilmente mobilizados e deixados às claras, já que o FBI se colocava publicamente como um bastião na luta contra o comunismo. Havia, portanto, regras de colocação de determinadas informações em cada parte de um documento, que por sua vez regiam o acesso ao conhecimento. Conhecer essas regras é não só conhecer os documentos, mas o funcionamento da agência que os produziu.

\section{Considerações finais}

Trabalhar com fontes de inteligência é uma tarefa árdua. Estabelecer um corpus documental coeso, interpretar as partes censuradas, lidar com nomes tarjados e conhecer os mecanismos de arquivo são desafios que fazem parte do trabalho que o historiador deve realizar com esse tipo de escrito. Embora esses documentos ofereçam informações que provavelmente seriam impossíveis de se conseguir de outra maneira, seu conteúdo é recheado de equívocos e julgamentos problemáticos. Ao mesmo tempo, as narrativas que envolvem as agências de inteligência são sedutoras o suficiente para vermos suas interpretações como legítimas e verdadeiras. Essas imagens de forças policiais e investigativas idôneas, apolíticas e profissionais permeiam a cultura popular, e reproduzem uma noção que não condiz com o exercício da crítica e da reflexão acadêmica sobre a atividade policial, seja ela criminal ou de inteligência.

Cabe ao historiador exercer uma crítica bem fundamentada à atuação dessas agências. Mobilizar o conhecimento teórico-metodológico sobre a atividade de inteligência, as informações sobre a documentação produzida por agências como o FBI e uma crítica às imagens institucionais criadas por elas, torna possível o uso dessas fontes sem que se reproduzam acriticamente os postulados que sustentavam as investigações e 
a própria existência dessas organizações. Esse trabalho crítico também é fundamental para a recuperação das memórias das vítimas da repressão política dessas agências, sem que a privacidade dessas pessoas seja violada por trabalhos de pouca sensibilidade e discernimento teórico (BAUER e GERTZ, 2017, p. 178).

As reflexões metodológicas sobre esse tipo de fonte nos ajudam a entender os mecanismos de produção de sentido nos inquéritos. A partir delas, conseguimos compreender os complexos processos de representação dos investigados, atentando para como determinados discursos são construídos e mobilizados para legitimar e intensificar uma vigilância constante àqueles considerados perigosos. Juntamente com a abordagem mais descritiva comum à historiografia do FBI, as considerações sobre as representações dos investigados podem constituir caminho viável para as pesquisas sobre a instituição, ajudando a tornar mais complexas as análises sobre a atividade de inteligência.

Por meio da coleta, mobilização e arquivamento das informações, o FBI foi capaz de produzir e reproduzir seu poder e sua faceta pública. Ao mesmo tempo, conseguiu controlar seus investigados, sabotando indivíduos, influenciando a opinião pública e investigando subversivos. Toda a gestão informacional do Bureau - as classificações, categorizações, mobilizações, relações de poder, os documentos e a circulação deles produziu determinadas imagens acerca de seus investigados. Nas palavras de Craig Robertson, "Nesse sistema de inteligência, o ato de classificar, ou de arquivar, transforma a identidade do referente" (ROBERTSON, 2006, p. 70).

\section{Referências bibliográficas}

BALL, Jared A. e BURROUGHS, Todd Steven. A Lie of Reinvention: Correcting Manning Marable's Malcolm X. Baltimore: Black Classic Press, 2012. E-book.

BAUER, Caroline Silveira e GERTZ, René E. "Fontes Sensíveis da história recente". In: LUCA, Tania Regina de e PINSKY, Carla Bassanezi (Orgs.). O historiador e suas fontes. São Paulo: Editora Contexto, 2017, pp. 173-193.

BUITRAGO, Ann Mari; IMMERMAN, Leon Andrew. Are You Now or Have You Ever Been in the FBI Files? How to Secure and Interpret Your FBI Files. New York: Grove Press, Inc., 1981.

CAMARgO, Ana Maria de Almeida. Os Arquivos da Polícia Política como Fonte. São Paulo: 1996.

Disponível

em: 
$<$ https://edisciplinas.usp.br/pluginfile.php/1987404/mod_resource/content/1/ACamargo _Os_arquivos.pdf>. Acesso em: 26 set. 2020.

CHARTIER, Roger. A História Cultural. Entre práticas e representações. Rio de Janeiro: Bertrand Brasil, 1988.

FARIA, J. P. M. O FBI de John Edgar Hoover: História e Historiografia. Anais do VI Encontro de Estudos dos Estados Unidos, 2019, pp. 39-56. Disponível em: $<$ http://historiadoseua.uff.br/wp-content/uploads/sites/113/2020/03/Anais-VI-

Eneua.pdf>. Acesso em: 26 set. 2020.

FICO, Carlos. Como Eles Agiam. Rio de Janeiro: Record, 2001.

FOUCAULT, Michel. Em Defesa da Sociedade. São Paulo: WMF Martins Fontes, 2010.

GARROW, David J. The FBI and Martin Luther King, Jr. New York: Penguin Books, 1988.

The Troubling Legacy of Martin Luther King Jr. Standpoint Magazine, 30 de maio de 2019. Disponível em: <https://standpointmag.co.uk/issues/june2019/the-troubling-legacy-of-martin-luther-king/>. Acesso em: 26 set. 2020.

HAGEDORN, Ann. Savage Peace: Hope and Fear in America, 1919. New York: Simon \& Schuster, 2007.

HAINES, Gerald K. e LANGBART, David A. Unlocking the Files of the FBI: A Guide to Its Records and Classification System. Wilmington: Rowman \& Littlefield Publishers, 1993.

HALL, Jacquelyn Dowd. "The Long Civil Rights Movement and the Political Uses of the Past”. In: The Journal of American History, Vol. 91, No. 4 (Mar. 2005), pp. 1233-1263.

HARTOG, François. O Espelho de Heródoto. Belo Horizonte: UFMG, 1999.

JEFFREYS-JONES, Rhodri. The FBI: A History. New Haven: Yale University Press, 2007.

JOHNSON, Loch K. (Org.). Handbook of Intelligence Studies. London and New York: Routledge, 2007.

MAY, Elaine Tyler. Fortress America: How We Embraced Fear and Abandoned Democracy. New York: Basic Books, 2017.

MAGALHÃES, Marionilde D. B. de. A lógica da suspeição: sobre os aparelhos repressivos À época da ditadura militar no Brasil. Revista Brasileira de História, vol. 17, n. 34, São Paulo, 1997. Disponível em < https://www.scielo.br/scielo.php?script=sci_arttext\&pid=S0102-01881997000200011>. Acesso em: 26 set. 2020.

O'REILLY, Kenneth. The FBI and the Origins of McCarthyism. The Historian, Vol. 45, No.3 (MAY 1983). 
O'REILLY, Kenneth. The FBI and the Civil Rights Movement during the Kennedy Years: from the Freedom Rides to Albany. The Journal of Southern History, vol. 54, $\mathrm{n}^{\mathrm{o}} 2$ (May, 1988), pp. 201-232.

O'REILLY, Kenneth. Racial Matters: The FBI's Secret File on Black America, 19601972. New York: Free Press, 1991.

PACCI, Mehmet. Political Misuse of Domestic Intelligence: A Case Study on the FBI. University of North Texas: Dissertação de Mestrado, 2002.

POWERS, Richard Gid. Broken: The Troubled Past and Uncertain Future of the FBI. New York: Free Press, 2004.

RANSBY, Barbara. A Black Feminist's Response to Attacks on Martin Luther King Jr.'s Legacy. The New York Times, 3 de junho de 2019. Disponível em: <https://www.nytimes.com/2019/06/03/opinion/martin-luther-king-fbi.html>. Acesso em: 26 set. 2020.

ROBERTSON, Craig. Mechanisms of Exclusion. In: RILES, Annelise (Org.). Documents: Artifacts of Modern Knowledge. University of Michigan Press, 2006

THEOHARIS, Athan. The FBI and American Democracy: A Brief Critical History. Kansas City: Kansas University Press, 2004.

TRAVANCAS, Isabel et al. (Orgs.). Arquivos Pessoais: Reflexões multidisciplinares e experiências de pesquisa. Rio de Janeiro: FGV, 2013. 